\title{
A retrospective observational analysis of red blood cell transfusion practices in stable, non-bleeding adult patients admitted to nine medical-surgical intensive care units
}

\author{
Lesley J. J. Soril ${ }^{1,2}$, Tom W. Noseworthy ${ }^{1,2}$, Henry T. Stelfox ${ }^{1,2,3}$, David A. Zygun ${ }^{4}$ and Fiona M. Clement ${ }^{1,2^{*}}$
}

\begin{abstract}
Background: Red blood cell (RBC) transfusions are common procedures performed in the intensive care unit (ICU). However, conservative transfusion approaches have been recommended to avoid RBC transfusions that are not clinically necessary and to achieve optimal patient outcomes. The objective of this study was to examine the utilization and costs of RBC transfusions in medical-surgical ICUs and to compare this information against clinical guideline recommendations for best practice.
\end{abstract}

Methods: Retrospective observational analysis of RBC transfusions in stable, non-bleeding adult patients was examined in a geographically-defined, population-based cohort of nine integrated ICUs between April 1, 2014 and December 31, 2016. RBC transfusions associated with a pre-transfusion hemoglobin value of $70 \mathrm{~g} / \mathrm{L}$ or more were examined through linear and logistic regression. The total costs of RBC transfusions, based on the RBC unit cost, were estimated.

Results: A total of 4632 RBC transfusions (2287 ICU admissions) were included. Pre-transfusion hemoglobin values were identified for 4487 transfusions. On average, $61 \%$ occurred at or above a hemoglobin value of $70 \mathrm{~g} / \mathrm{L}$ (mean $73.4 \pm 9.2 \mathrm{~g} / \mathrm{L}$ ). Factors associated with such transfusions included being male, age over 75 , Sequential Organ Failure Assessment (SOFA) score greater or equal to 10, transfer from operating room, gastrointestinal bleeding, and trauma. A pre-transfusion hemoglobin value at or above $70 \mathrm{~g} / \mathrm{L}$ was associated with increased odds of ICU mortality; there was no impact on overall hospital mortality. The total estimated cost of RBC transfusions was \$2.99M Canadian dollars (CAD), with \$1.82M CAD attributed to those with a hemoglobin value at or above $70 \mathrm{~g} / \mathrm{L}$.

Conclusions: Over half of the examined RBC transfusions may not have aligned with recommended best practice; this suggests significant opportunity for improvement. The present findings are an essential step towards optimizing RBC transfusions in the ICU.

Keywords: Red blood cells, Blood transfusion, Restrictive transfusion threshold, Liberal transfusion threshold, Intensive care unit, Overuse

\footnotetext{
* Correspondence: fclement@ucalgary.ca

${ }^{1}$ Department of Community Health Sciences, Cumming School of Medicine,

University of Calgary, 3D18, Teaching Research and Wellness Building, 3280

Hospital Drive NW, Calgary, Alberta T2N 4N1, Canada

${ }^{2} \mathrm{O}$ 'Brien Institute for Public Health, University of Calgary, 3280 Hospital Drive

NW, Calgary, Alberta T2N 4N1, Canada

Full list of author information is available at the end of the article
}

(c) The Author(s). 2019 Open Access This article is distributed under the terms of the Creative Commons Attribution 4.0 International License (http://creativecommons.org/licenses/by/4.0/), which permits unrestricted use, distribution, and reproduction in any medium, provided you give appropriate credit to the original author(s) and the source, provide a link to the Creative Commons license, and indicate if changes were made. The Creative Commons Public Domain Dedication waiver (http://creativecommons.org/publicdomain/zero/1.0/) applies to the data made available in this article, unless otherwise stated. 


\section{Background}

The need to address medical overuse, defined as "the provision of medical services for which the potential for harm exceeds the potential for benefit" [1], is increasingly being recognized by healthcare systems internationally [25]. In 2012, the Joint Commission on medical overuse in the USA identified a list of the top five overused medical procedures based on available evidence and expert-recommended standards of appropriateness [6]; among those listed was the over-transfusion of blood and blood products, such as red blood cells (RBCs).

Allogeneic RBC transfusion is a common procedure for many medical and surgical specialties and is typically used to manage hemorrhagic or anemic events among hospitalized patients [7-11]. However, with the risks of infection or even mortality associated with RBC transfusions, overuse is of significant concern for patient safety and quality of care $[12,13]$. Beyond this, blood products are costly resources and are limited in their availability; current estimates suggest that acquisition and administration costs for RBC transfusions range internationally from $\$ 500$ to $\$ 1200$ USD per $\mathrm{RBC}$ unit transfused [14]. Blood conservation is, therefore, additionally important to maintaining financial stewardship in healthcare systems worldwide.

To guide appropriate use of RBC transfusion, clinical guidelines such as those from the AABB (formerly the American Association of Blood Banks) [15] have developed evidence-based recommendations predicated on set pre-transfusion hemoglobin concentration values. For example, for most stable, non-bleeding hospitalized patients, including those admitted to the intensive care unit (ICU), RBC transfusions are not recommended above a hemoglobin level of $70 \mathrm{~g} / \mathrm{L}$ [15]. Informing such recommendations are a number of randomized controlled trials (RCTs) that have examined the efficacy of a restrictive (e.g., hemoglobin value of $70 \mathrm{~g} / \mathrm{L}$ ) versus a liberal transfusion strategy (e.g., hemoglobin value of 100 g/L). [16-20]. A recent systematic review of 31 RCTs found that, with the exception of certain high-risk groups (i.e., neurological injury or disorders, acute coronary syndrome), a restrictive transfusion strategy decreased transfusion requirements without increasing the risk of mortality and adverse outcomes for most hospitalized patients [21].

Given this established evidence base, the primary objective of this retrospective observational study was to measure the utilization and costs of RBC transfusion practices among medical-surgical ICUs and to compare this information to recommended best practice.

\section{Methods}

\section{Study design and setting}

For this multi-center, retrospective observational study, all RBC transfusion events in nine adult ICUs in Alberta,
Canada, were examined between April 1, 2014 and December 31, 2016. The included ICUs are mixed medical and surgical units situated within academic, tertiary, and large urban or regional hospitals. Attending physicians (i.e., intensivists) are accountable for the medical care delivery in each ICU, with clinical coverage provided by post-graduate medical education trainees in most units [22]. Therefore, orders for laboratory tests and procedures, such as RBC transfusions, are made at the discretion of the attending intensivists or their delegates.

\section{Study population}

Critically ill patients 18 years of age or older, who were (a) admitted to one of the nine adult ICUs and with a length-of-stay more than $24 \mathrm{~h}$, (b) received at least one packed RBC transfusion during their ICU stay, and (c) captured in the eCritical database (see the "Data sources" section below), were included.

ICU patients were excluded for any of the following reasons: age less than 18 years, evidence of active blood loss, primary or secondary diagnosis of anemia, pregnancy, brain death or imminent death within $24 \mathrm{~h}$, primary diagnosis of neurocritical illness, primary or secondary diagnosis of acute myocardial infarction, and admission after a routine cardiac surgical procedure. The definitions for each exclusion criterion are provided in Table 1, and complete operational definitions are provided in Additional file 1.

Table 1 Exclusion criteria for study cohort

\begin{tabular}{|c|c|}
\hline Exclusion criteria & Definition(s) \\
\hline Not an adult & Age less than 18 years at time of ICU admission \\
\hline \multirow[t]{4}{*}{$\begin{array}{l}\text { Active blood loss prior } \\
\text { to transfusion }\end{array}$} & $\begin{array}{l}\text { Decrease in Hgb of } 30 \mathrm{~g} / \mathrm{L} 12 \mathrm{~h} \text { before the } \\
\text { index transfusion }\end{array}$ \\
\hline & $\begin{array}{l}3 \text { units }(900 \mathrm{~mL} \text { ) of RBC } 12 \mathrm{~h} \text { before the index } \\
\text { transfusion }\end{array}$ \\
\hline & $\begin{array}{l}\text { One or more transfusions } 12 \mathrm{~h} \text { after the index } \\
\text { transfusion }\end{array}$ \\
\hline & Other indicators of active blood loss \\
\hline Anemia & Primary or secondary diagnosis of anemia \\
\hline Pregnancy & Pregnant state during in-hospital stay \\
\hline $\begin{array}{l}\text { Brain death or } \\
\text { imminent death }\end{array}$ & $\begin{array}{l}\text { Indication of clinical brain death in ICU or } \\
\text { death within } 24 \mathrm{~h} \text { of ICU admission }\end{array}$ \\
\hline $\begin{array}{l}\text { Acute myocardial } \\
\text { infarction (AMI) }\end{array}$ & Primary or secondary diagnosis of AMI \\
\hline Neurocritical illness & $\begin{array}{l}\text { Critically ill patients with neurological injury or } \\
\text { condition of the brain requiring intensive care } \\
\text { treatment (e.g., traumatic brain injury, } \\
\text { intracerebral, or subarachnoid hemorrhage) }\end{array}$ \\
\hline $\begin{array}{l}\text { ICU admission after } \\
\text { routine cardiac surgery }\end{array}$ & $\begin{array}{l}\text { ICU admission of post-operative cardiac } \\
\text { patients (e.g., coronary artery bypass grafting) }\end{array}$ \\
\hline
\end{tabular}




\section{Data sources}

The primary data source was the clinical information system eCritical Alberta [23]. eCritical captures comprehensive data on each ICU admission and enables electronic documentation of patient information at the bedside. eCritical is also linked to an integrated clinical analytics and data warehouse system for all ICU patient data in the province [23]. Specifically for this study, the information obtained from eCritical included patient demographics (e.g., age, sex); diagnostic or case-mix (e.g., primary ICU admission diagnoses, secondary chronic conditions, Acute Physiology and Chronic Health Evaluation [APACHE] II, and Sequential Organ Failure Assessment [SOFA] scores); treatment data (e.g., RBC transfusions); laboratory data (e.g., hemoglobin measurements); and outcomes (e.g., ICU length of stay [LOS] and mortality). The start of the study period aligns to the commencement of data collection from all of the nine ICUs included in the eCritical system.

A secondary data source, the Canadian Institute for Health Information (CIHI) Discharge Abstract Database (DAD), which collects standardized administrative aspects of in-hospital care [24], was used to analyze information on hospital LOS, Charlson comorbidity index scores, 30-day and 60-day readmission to hospital, and in-hospital mortality. Each patient was assigned a unique personal identifier to permit linkage of patient information across databases.

\section{Primary and secondary outcomes}

The primary outcome was the proportion of RBC transfusions associated with a pre-transfusion hemoglobin value greater than or equal to $70 \mathrm{~g} / \mathrm{L}$. The pre-transfusion hemoglobin value was defined as the most proximal hemoglobin measurement obtained within $24 \mathrm{~h}$ prior to the transfusion; this was assumed to be the threshold at which a transfusion was initiated. Secondary outcomes included ICU and hospital LOS and mortality.

\section{Data analysis}

Patient and RBC transfusion characteristics were examined using descriptive statistics. Continuous data was presented as means and standard deviations (SD) or, if non-normal, as medians with interquartile ranges (IQR). The aggregate frequencies and percentages of $\mathrm{RBC}$ transfusion events within pre-transfusion hemoglobin ranges were depicted in tables and graphical form. For each month of the study period, the percentage of RBC transfusion events with a pre-transfusion hemoglobin value at or above $70 \mathrm{~g} / \mathrm{L}$ was estimated and plotted with the $95 \%$ confidence interval (CI) over the 33 months. Simple linear regression was performed to examine the month-to-month change in the proportion of $\mathrm{RBC}$ transfusions associated with a pre-transfusion hemoglobin value above $70 \mathrm{~g} / \mathrm{L}$ across the study period. In addition, multiple logistic and linear regression were performed to examine the association between (a) patient characteristics and the primary outcome and (b) pre-transfusion hemoglobin values of $70 \mathrm{~g} / \mathrm{L}$ or more and the secondary outcomes. Clinically important covariates were incorporated into the final adjusted models and included: sex; age; APACHE II score; SOFA score; location prior to ICU admission (e.g., emergency department, operating room, or recovery room); ICU admit diagnostic category; Charlson comorbidity index score; mechanical ventilation status; and overnight timing of transfusion (i.e., between 19:00 and 7:00). Measures of effect estimated from logistic regression analyses were reported as unadjusted and adjusted odds ratios (OR) and $95 \% \mathrm{CI}$. Regression coefficients $\left(\beta_{1}\right)$, standard errors $(\mathrm{SE}), 95 \% \mathrm{CI}$, and $r$-squared values were reported from linear regression analyses.

Total costs for all RBC transfusions and the potential cost savings from eliminating transfusion events with a pre-transfusion hemoglobin value at or above $70 \mathrm{~g} / \mathrm{L}$, within 5-10 g/L increments, were estimated. The cost of transfusing a single $\mathrm{RBC}$ unit in Alberta was estimated to be $\$ 666.10$ Canadian dollars (CAD) from a previous activity-based costing study [25]. Given that the volume of a RBC unit can vary between 250 and $350 \mathrm{~mL}$, it was assumed that the volume of a $1 \mathrm{RBC}$ unit was equal to $300 \mathrm{~mL}$ in order to estimate the number of $\mathrm{RBC}$ units transfused per transfusion event [26]. Costs are reported in 2017 CAD. All data analyses were completed using STATA $13.1 \mathrm{IC}$.

\section{Results}

\section{ICU patient characteristics}

A total of 2287 ICU admissions, comprised of 2142 unique patients who received at least one RBC transfusion and had a minimum ICU LOS of $24 \mathrm{~h}$, were included (Table 2). The admissions included in the final cohort represented $10.9 \%$ of all ICU admissions in the nine participating ICUs during the 33-month study period (2287 out of 4234 admissions). A flow chart of the included RBC transfusion events during these ICU admissions is provided in Fig. 1. Most RBC transfusions were excluded due to evidence of active blood loss or hemorrhage, a primary diagnosis of neurocritical illness, and a primary or secondary diagnosis of acute myocardial infarction.

The characteristics of the included cohort are summarized in Table 2. Most patients were under the age of 65 (mean age $58.6 \pm 15.5$ years) and male (54.2\%). The primary ICU admission diagnosis for this cohort was infection $(26.8 \%)$, and the mean APACHE II and SOFA scores were $24.4 \pm 8.0$ and $9.1 \pm 4.1$, respectively. Almost half of the ICU admissions were transferred from the 
Table 2 Characteristics of ICU patients receiving a RBC transfusion between April 1, 2014 and December 31, 2016

\begin{tabular}{|c|c|c|c|}
\hline Characteristic & Total frequency & inued) & \\
\hline Total included ICU admissions, $n$ & 2287 & Characteristic & Total frequency \\
\hline Unique patients & 2142 & Median hospital, days (IQR) & $25.5(37.5)$ \\
\hline Mean age, years (SD) & $58.6(15.5)$ & Mean hospital, days (SD) & $40.7(45.5)$ \\
\hline$<55$ years, $n(\%)$ & $810(35.4)$ & Readmission, $n$ (\%) & \\
\hline $55-64$ years, $n(\%)$ & $594(26.0)$ & ICU within $72 \mathrm{~h}$ & $61(2.7)$ \\
\hline $65-74$ years, $n(\%)$ & $537(23.5)$ & Hospital within 30 days & $330(14.4)$ \\
\hline$\geq 75$ years, $n(\%)$ & $346(15.1)$ & Hospital within 60 days & $497(21.7)$ \\
\hline Gender, $n(\%)$ & & Mortality, n (\%) & \\
\hline Male & $1240(54.2)$ & ICU mortality & $430(18.8)$ \\
\hline Female & $1047(45.8)$ & Hospital mortality & $664(29.0)$ \\
\hline
\end{tabular}

Mean APACHE II score (SD)

APACHE II score $\leq 20, n(\%)$

APACHE II score $>20, n(\%)$

Mean SOFA score (SD)

SOFA score $<10, n(\%)$

SOFA score $\geq 10, n(\%)$

Location transferred from, $n(\%)$

Emergency department

Operating or recovery room

Other ICU

Other

ICU admit diagnostic category (or surgery for), $n(\%)$

Infection

Gastrointestinal

Gastrointestinal bleeding

Sepsis

Cardiovascular

Hepatic-renal

Respiratory

Trauma

Pancreatic

Cancer

Orthopedic

Drug overdose

Other

Charlson comorbidity index, $n$ (\%)

0

1

$\geq 2$

Mechanical ventilation, $n$ (\%)

Length of stay

Median ICU, days (IQR)

Mean ICU, days (SD)
Table 2 Characteristics of ICU patients receiving a RBC transfusion between April 1, 2014 and December 31, 2016 (Continued)

emergency department (29.4\%) or the operating or recovery room (19.6\%), and the median ICU LOS was just over a week (8.1 days, IQR 11.2). Readmission to the ICU within $72 \mathrm{~h}$ was less than $3 \%(n=61)$, and ICU mortality was $18.8 \%(n=430)$.

\section{RBC transfusion events and pre-transfusion hemoglobin values}

The frequencies of RBC transfusion events are provided in Table 3. A total of $4632 \mathrm{RBC}$ transfusions were identified among the included ICU admissions; this represented approximately $26.7 \%$ of all $\mathrm{RBC}$ transfusions during the study period (Fig. 1). Assuming that 1 RBC unit was equal to 300 $\mathrm{mL}$ [26], approximately $1 \mathrm{RBC}$ unit was transfused per transfusion event, with two transfusion events occurring per ICU admission. With regards to the timing of the RBC transfusion orders, approximately $46 \%$ occurred during overnight shifts (i.e., between 19:00 and 07:00) (Table 3).

Pre-transfusion hemoglobin values were identified for 4487 of the RBC transfusions (Table 3), and the mean pre-transfusion hemoglobin value was $73.4 \pm 9.2 \mathrm{~g} / \mathrm{L}$. The distribution of pre-transfusion hemoglobin values within specific ranges is also depicted in Fig. 2. On average, $61 \%$ of the included RBC transfusions had a pre-transfusion hemoglobin value greater than or equal to $70 \mathrm{~g} / \mathrm{L} \quad(n=2739)$, and $19.7 \% \quad(n=885)$ had a pre-transfusion hemoglobin value greater than or equal to $80 \mathrm{~g} / \mathrm{L}$ (Fig. 2; Table 3). The patient characteristics for each of the RBC transfusion events, stratified in three pre-transfusion hemoglobin groups (less than $70 \mathrm{~g} / \mathrm{L}$, between 70 and $79 \mathrm{~g} / \mathrm{L}$, greater than or equal to $80 \mathrm{~g} / \mathrm{L}$ ) are also provided in Additional file 2. The monthly proportions of RBC transfusions with hemoglobin values greater than or equal to $70 \mathrm{~g} / \mathrm{L}$ over the study period are presented in Fig. 3. Simple linear regression revealed that there was a significant decrease in the proportion of these transfusions over the 33 months $(\beta 1-0.706 ; p<$ 0.0001) (Additional file 3). 


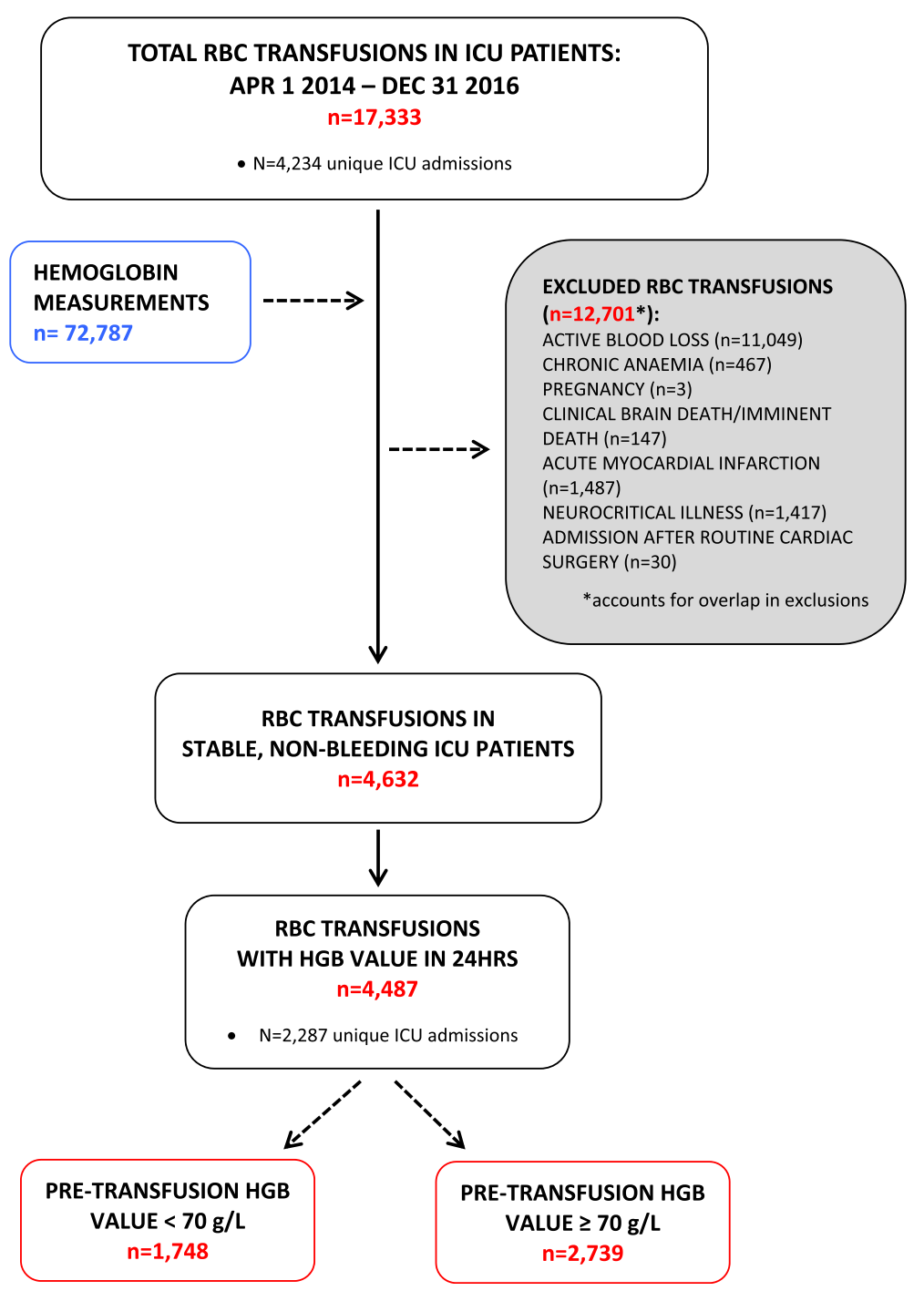

Fig. 1 Flow chart of included RBC transfusion events

Table 3 Summary of RBC transfusions and pre-transfusion hemoglobin values

\begin{tabular}{ll}
\hline Variable & All ICUs \\
\hline Total RBC transfusion events, $n$ & 4632 \\
$\quad$ Mean number of transfusions per admission & 2.0 \\
Total volume of RBCs transfused, $\mathrm{mL}$ & $1,356,695$ \\
$\quad$ Mean number of RBC units per transfusion & 1.0 \\
Overnight transfusions (between 19:00 and 7:00), $n$ (\%) & $2120(45.8)$ \\
Transfusions with hemoglobin measurements $\leq 24 \mathrm{~h}, n(\%)$ & $4487(96.9)$ \\
Mean number of hours pre-transfusion (SD) & $6.3(5.3)$ \\
Mean pre-transfusion hemoglobin value, g/L (SD) & $73.4(9.2)$ \\
\hline
\end{tabular}

Factors associated with pre-transfusion hemoglobin value Several factors associated with a pre-transfusion hemoglobin level greater than or equal to $70 \mathrm{~g} / \mathrm{L}$ were identified through multiple logistic regression (Table 4). Specifically, males (OR 1.20, 95\% CI 1.06-1.35), over 75 years of age (OR 1.45, 95\% CI 1.16-1.80), SOFA score greater than or equal to 10 (OR 1.18, 95\% CI 1.02-1.37), admitted to the ICU from an operating or recovery room (OR 1.47, 95\% CI 1.21-1.79), and admitted to the ICU due to gastrointestinal bleeding (OR 2.59, 95\% CI 1.50-4.46) or trauma (OR 1.88, 94\% CI 1.31-2.69) were all associated with increased odds of having a RBC transfusion with a pre-transfusion hemoglobin value greater than or equal to $70 \mathrm{~g} / \mathrm{L}$. In contrast, the odds were significantly decreased if the $\mathrm{RBC}$ transfusion occurred overnight (i.e., between 19:00 and 7:00) (OR 0.69, 95\% CI 0.61-0.78) (Table 4). 


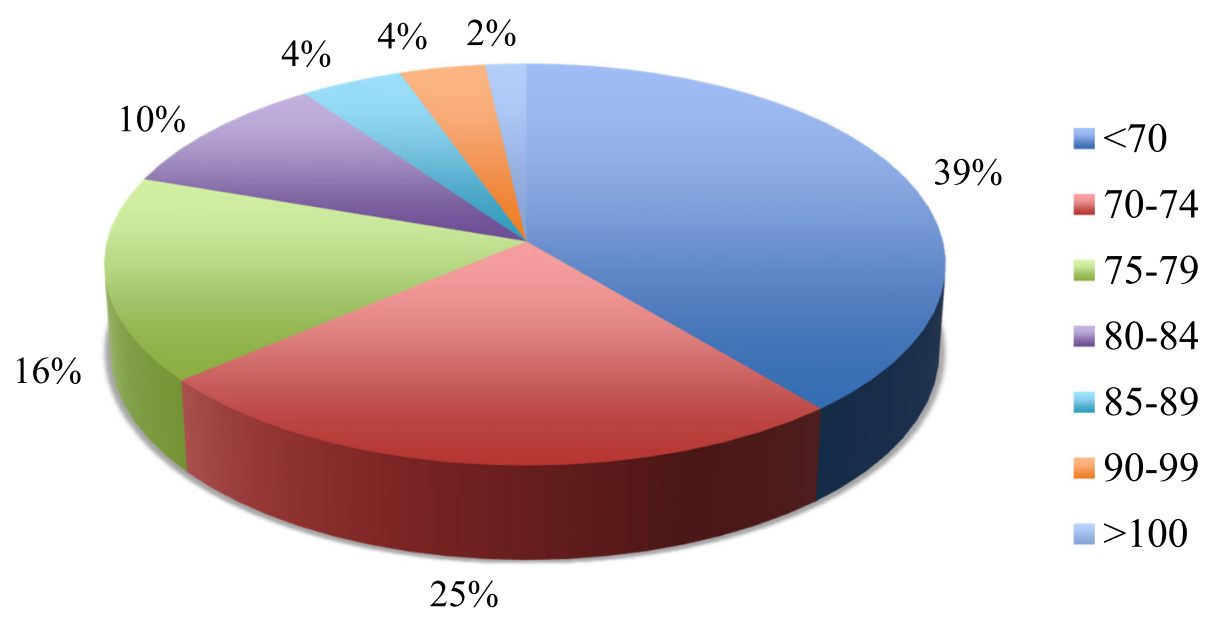

Fig. 2 Distribution of pre-transfusion hemoglobin values in grams per liter ranges

Impact of pre-transfusion hemoglobin values on length of stay and mortality

Having at least one transfusion with a hemoglobin value at or above $70 \mathrm{~g} / \mathrm{L}$ was associated with a decrease in ICU LOS $\left(\beta_{1}-1.63 ; p=0.029\right)$ and hospital LOS $\left(\beta_{1}-5.36 ; p=0.002\right)$ (Table 5). The association between pre-transfusion hemoglobin value and mortality differed between the ICU and hospital. The adjusted odds of ICU mortality were increased (OR 1.23, 95\% CI 1.06-1.44) if a transfusion event was associated with a pre-transfusion hemoglobin of $70 \mathrm{~g} / \mathrm{L}$ or more; there was no association with hospital mortality (OR 1.14, 95\% CI 0.99-1.31) (Table 6).

\section{Estimated costs of RBC transfusions}

The estimated costs of included RBC transfusion events and potential healthcare cost savings from eliminating transfusions with a hemoglobin level of $70 \mathrm{~g} / \mathrm{L}$ or more, presented within 5-10 g/L increments, are summarized in Table 7. Assuming $1 \mathrm{RBC}$ unit was transfused per event, the total estimated cost of $4487 \mathrm{RBC}$ units (i.e., transfusions with an identified hemoglobin value) was approximately $\$ 2.99 \mathrm{M}$ CAD. If the $79 \mathrm{RBC}$ transfusion events with a hemoglobin value at or above $100 \mathrm{~g} / \mathrm{L}$ were eliminated, the estimated cost savings from those transfusion events alone would be $\$ 52,622$ CAD. Further, if all 2739 transfusions with a hemoglobin value at or above $70 \mathrm{~g} / \mathrm{L}$ were avoided, the estimated cost savings would increase to approximately \$1.82M CAD.

\section{Discussion}

In this multi-center, retrospective observational study, the RBC transfusion practices in nine adult medical-surgical ICUs were examined. We identified a total of 4632 unique RBC transfusions events in 2287 mixed medical and surgical ICU admissions. Patients within this cohort received approximately two transfusions per ICU admission, with 1 RBC unit transfused per event, and had a mean pre-transfusion hemoglobin

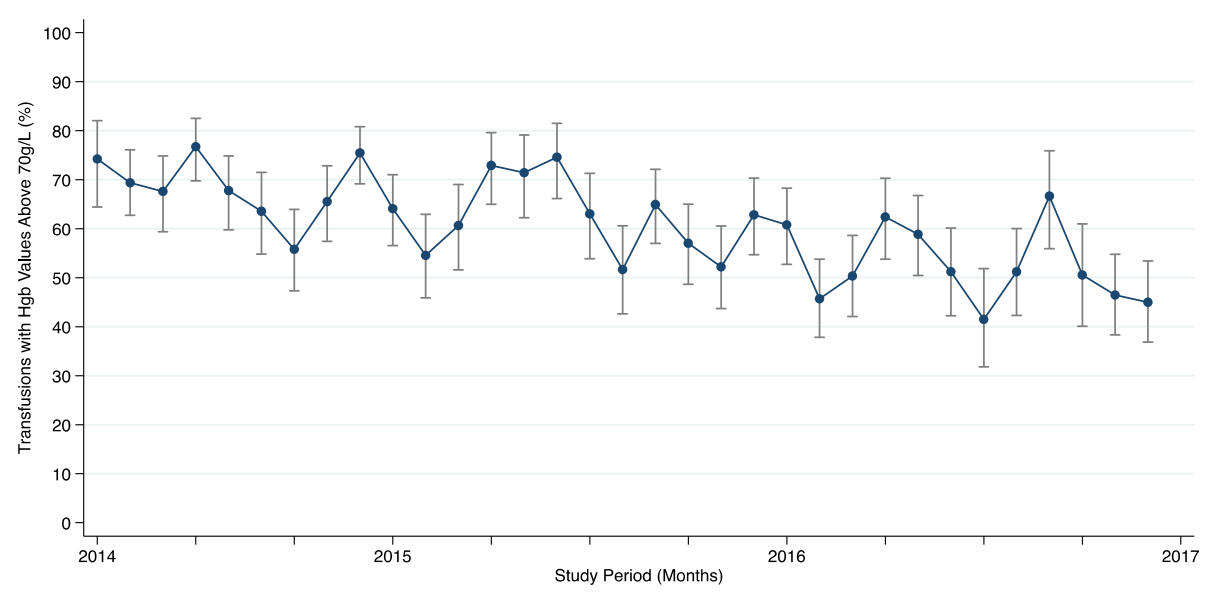

Fig. 3 Monthly percentages of RBC transfusion with pre-transfusion hemoglobin values of $70 \mathrm{~g} / \mathrm{L}$ or more 
Table 4 Factors associated with a pre-transfusion hemoglobin value of $70 \mathrm{~g} / \mathrm{L}$ or more

\begin{tabular}{|c|c|c|c|c|}
\hline & Unadjusted & & Adjusted OP & \\
\hline Covariates & $\mathrm{OR}$ & $95 \% \mathrm{Cl}$ & OR & $95 \% \mathrm{Cl}$ \\
\hline Male & 1.21 & $1.07-1.37$ & 1.20 & $1.06-1.35$ \\
\hline \multicolumn{5}{|l|}{ Age category } \\
\hline$<55$ & Reference & & Reference & \\
\hline $55-64$ & 1.04 & $0.90-1.22$ & 1.04 & $0.89-1.22$ \\
\hline $65-74$ & 1.10 & $0.94-1.29$ & 1.08 & $0.91-1.28$ \\
\hline$\geq 75$ & 1.48 & $1.21-1.82$ & 1.45 & $1.16-1.80$ \\
\hline APACHE I| score $>20$ & 1.05 & $0.92-1.20$ & 1.05 & $0.89-1.23$ \\
\hline SOFA score $\geq 10$ & 1.14 & $1.01-1.28$ & 1.18 & $1.02-1.37$ \\
\hline \multicolumn{5}{|l|}{ Location before ICU admission } \\
\hline Other & Reference & & Reference & \\
\hline Emergency department & 1.11 & $0.96-1.27$ & 1.09 & $0.95-1.26$ \\
\hline Operating or recovery room & 1.59 & $1.33-1.89$ & 1.47 & $1.21-1.79$ \\
\hline Other ICU & 1.13 & $0.76-1.66$ & 1.14 & $0.76-1.70$ \\
\hline \multicolumn{5}{|l|}{ ICU admit diagnostic category } \\
\hline Other & Reference & & Reference & \\
\hline Infection & 0.83 & $0.66-1.04$ & 0.79 & $0.62-1.00$ \\
\hline Gastrointestinal & 1.37 & $1.05-1.78$ & 1.17 & $0.89-1.54$ \\
\hline Gastrointestinal bleeding & 2.43 & $1.42-4.15$ & 2.59 & $1.50-4.46$ \\
\hline Sepsis & 1.19 & $0.91-1.57$ & 1.17 & $0.88-1.56$ \\
\hline Cardiovascular & 1.38 & $1.04-1.83$ & 1.31 & $0.98-1.75$ \\
\hline Hepatic-renal & 0.88 & $0.65-1.19$ & 0.84 & $0.62-1.15$ \\
\hline Respiratory & 0.74 & $0.53-1.03$ & 0.75 & $0.53-1.05$ \\
\hline Trauma & 2.01 & $1.42-2.84$ & 1.88 & $1.31-2.69$ \\
\hline Pancreatic & 0.93 & $0.64-1.36$ & 0.95 & $0.65-1.40$ \\
\hline Cancer & 0.92 & $0.53-1.59$ & 0.73 & $0.42-1.29$ \\
\hline Orthopedic & 1.51 & $0.78-2.93$ & 1.31 & $0.66-2.57$ \\
\hline Drug overdose & 1.54 & $0.65-3.63$ & 1.63 & $0.69-3.89$ \\
\hline \multicolumn{5}{|l|}{ Charlson comorbidity index } \\
\hline 0 & Reference & & Reference & \\
\hline 1 & 0.98 & $0.83-1.16$ & 1.00 & $0.84-1.19$ \\
\hline$\geq 2$ & 1.06 & $0.92-1.23$ & 1.07 & $0.92-1.25$ \\
\hline Mechanical ventilation & 1.06 & $0.87-1.29$ & 1.06 & $0.86-1.31$ \\
\hline Transfused overnight (between 19:00 and 7:00) & 0.71 & $0.63-0.80$ & 0.69 & $0.61-0.78$ \\
\hline
\end{tabular}

Table 5 Associations between RBC transfusions with a hemoglobin value of $70 \mathrm{~g} / \mathrm{L}$ or more and ICU and hospital length of stay

\begin{tabular}{llllll}
\hline Outcome & $\beta_{1}$ & SE & $95 \% \mathrm{Cl}$ & $r^{2}$ & $p$ value \\
\hline ICU LOS & -1.63 & 0.75 & -3.09 to -0.17 & 0.19 & 0.029 \\
Hospital LOS & -5.36 & 1.76 & -8.81 to -1.91 & 0.09 & 0.002 \\
\hline
\end{tabular}

Table 6 Associations between RBC transfusions with a hemoglobin value of $70 \mathrm{~g} / \mathrm{L}$ or more and ICU and hospital mortality

\begin{tabular}{llllll}
\hline & \multicolumn{2}{l}{ Unadjusted OR } & & \multicolumn{2}{l}{ Adjusted OR } \\
\cline { 2 - 3 } Outcome & OR & $95 \% \mathrm{Cl}$ & & OR & $95 \% \mathrm{Cl}$ \\
\hline ICU mortality & 1.20 & 1.04 to 1.38 & & 1.23 & 1.06 to 1.44 \\
Hospital mortality & 1.14 & 1.00 to 1.29 & & 1.14 & 0.99 to 1.31 \\
\hline
\end{tabular}


Table 7 Estimated costs of included RBC transfusion events between April 1, 2014 and December 31, 2016

\begin{tabular}{lll}
\hline Variable & Frequency $(n)$ & Total Costs $^{1}\left(\$ \mathrm{CAD}^{\prime}\right)$ \\
\hline RBC transfusion events with pre-transfusion hemoglobin values & 4487 & $2.99 \mathrm{M}$ \\
Cost savings from eliminating transfusions with: & & \\
Pre-transfusion hemoglobin value $\geq 100 \mathrm{~g} / \mathrm{L}$ & 79 & 52,622 \\
Pre-transfusion hemoglobin value $\geq 90 \mathrm{~g} / \mathrm{L}$ & 244 & 162,528 \\
Pre-transfusion hemoglobin value $\geq 85 \mathrm{~g} / \mathrm{L}$ & 441 & 293,750 \\
Pre-transfusion hemoglobin value $\geq 80 \mathrm{~g} / \mathrm{L}$ & 885 & 589,499 \\
Pre-transfusion hemoglobin value $\geq 75 \mathrm{~g} / \mathrm{L}$ & 1626 & $1.08 \mathrm{M}$ \\
Pre-transfusion hemoglobin value $\geq 70 \mathrm{~g} / \mathrm{L}$ & 2739 & $1.82 \mathrm{M}$ \\
\hline
\end{tabular}

'Estimates assume that the cost of a RBC unit is $\$ 666.10$; all costs are reported in 2017 CAD

level of $73.4 \mathrm{~g} / \mathrm{L}$. Among 4487 RBC transfusion events, $61 \%$ were associated with a pre-transfusion hemoglobin value at or above $70 \mathrm{~g} / \mathrm{L}$. Over the 33-month study period, this was estimated to cost over $\$ 1.8 \mathrm{M}$ CAD to the healthcare system. Factors such as being male, 75 years of age or older, admission to the ICU from the operating room, and an ICU admission diagnosis of gastrointestinal bleeding or trauma were positively associated with $\mathrm{RBC}$ transfusions events with a hemoglobin value greater or equal to $70 \mathrm{~g} / \mathrm{L}$. Moreover, having a pre-transfusion hemoglobin value at or above $70 \mathrm{~g} / \mathrm{L}$ was also associated with an increase in ICU mortality. There was no impact on overall hospital mortality.

We specifically sought to examine RBC transfusions among critically ill patients for whom a restrictive transfusion strategy is supported by the most current, high-quality evidence [16-21]. In doing so, we acknowledged that a restrictive pre-transfusion hemoglobin threshold will not apply in all clinical situations. For instance, in some hemorrhagic or ischemic events, clinical judgment should subvert laboratory value-based thresholds. To account for such reasonable clinical exclusions, we excluded from analysis a considerable number of patients (i.e., greater than $50 \%$ of ICU admissions with a $\mathrm{RBC}$ transfusion event) for whom a restrictive transfusion strategy has not been proven safe, nor superior, to a liberal transfusion strategy (e.g., chronic anemia, active blood loss, acute coronary syndrome, myocardial infarction, and neurological or traumatic brain injury) [21]. With our final cohort, we, therefore, aimed to decrease the potential for misclassifying a RBC transfusion event-for which a restrictive transfusion approach would not be appropriate-and allowed a conservative evaluation of RBC transfusion practices in the ICU.

Reduced exposure to RBCs, through the adoption of a restrictive pre-transfusion hemoglobin threshold (i.e., less than $70 \mathrm{~g} / \mathrm{L}$ ), has been increasingly recognized in transfusion guidelines as the best practice for most stable, non-bleeding adult patients in the ICU $[7,15,27$, $28]$. Within our cohort, we found that over half of all examined RBC transfusions may have occurred outside of the recommended best practice. While these findings suggest potential over-transfusion in the ICU, there have been minor improvements in transfusion practices over time. The reason for this is unknown but is likely the result of increasing awareness and attention to the subject. We also found that over $40 \%$ of RBC transfusions examined in our study were associated with a pre-transfusion hemoglobin value between $70 \mathrm{~g} / \mathrm{L}$ and $79 \mathrm{~g} / \mathrm{L}$. Visual inspection of the stratified patient characteristics (Additional file 2) did not suggest differences between transfusions associated with a hemoglobin value below $70 \mathrm{~g} / \mathrm{L}$ and $70-79 \mathrm{~g} / \mathrm{L}$. Interestingly, previous qualitative studies that have examined factors influencing physician transfusion behaviors found the greatest uncertainty among physicians when deciding whether to transfuse patients with a hemoglobin level within this borderline range $[29,30]$. Such uncertainty may similarly be reflected in our findings, and targeted efforts to better inform physician decision-making for transfusing such patients may be warranted.

Similar studies examining the appropriateness of RBC transfusion practices have been described in the literature. Previous retrospective audits, for example, have primarily focused on characterizing mean pre-transfusion hemoglobin levels and found them to range substantially between $71 \mathrm{~g} / \mathrm{L}$ and $91 \mathrm{~g} / \mathrm{L}$ for most non-hemorrhagic, ICU patient populations [31-34]. One of the larger studies conducted in the USA, a longitudinal analysis RBC transfusion practice between 1997 and 2007, reported a similar mean pre-transfusion hemoglobin level to our patient cohort after their 10 year follow-up period (significantly decreasing from $79 \pm 1.3$ to $73 \pm 1.3 \mathrm{~g} / \mathrm{L}$ ) [32]. In addition, Netzer et al. [32] observed a significant decrease in the proportion of patients who were transfused at a hemoglobin level of less than 70 $\mathrm{g} / \mathrm{L}$. In contrast, studies that have examined average transfusion volumes have reported higher numbers of RBC units per transfusion event compared to our study results, ranging from 2 to $4.3 \mathrm{RBC}$ units [32, 35]. While it is difficult to reconcile specific reasons for observed differences between these previous studies and our present findings, some differences are likely attributable to variations in the patient 
case-mix, ICU structure or culture, or even the time since the publication (and acceptance) of seminal and relevant literature and guidelines.

We conducted additional analytical investigations that represent novel contributions to the existing literature and offer considerations for policy and practice, as well as future research. The costing analysis, for instance, enabled the valuation of not only RBC transfusions across the ICUs, but also of the opportunity cost of potentially inappropriate practices over the 33-month study period. Presenting such costing outcomes provides another perspective for clinical experts to reflect on as the stewards of healthcare resources. This information can also help healthcare system decision-makers implement interventions whose implementation costs could still yield a reasonable return on investment and, as such, improve the overall efficiency of care delivered.

We also identified several factors associated with RBC transfusions with a hemoglobin level above $70 \mathrm{~g} / \mathrm{L}$. In particular, ICU admission diagnoses of gastrointestinal bleeding and trauma were associated with at least a 30$50 \%$ increase in the odds of these transfusions. Despite the evidence supporting the use of a restrictive $\mathrm{RBC}$ transfusion strategy for both of these patient groups [21], as well as our exclusion of transfusions among patients with active bleeding, the propensity for hemorrhagic outcomes with such conditions may account for the increased odds in the observed cases [36, 37]. Due to the overlap in $95 \%$ confidence intervals across point estimates, we did not find any one (or few) factor(s) that markedly increased the odds of transfusion over other factors. This suggests that there may be several drivers, both characterized and uncharacterized (e.g., level of physician experience, cultural influences) in our present work that act in concert and underlie the observed proportion of overuse.

In addition, the downstream impacts of pre-transfusion hemoglobin values in our transfused patient cohort differed by ICU and hospital. With respect to mortality, we found that the odds in the ICU were increased for transfused patients with a pre-transfusion hemoglobin of $70 \mathrm{~g} / \mathrm{L}$ or more, but there was no difference in hospital deaths. Previous meta-analyses of RCTs comparing restrictive versus liberal hemoglobin thresholds found that there was no difference in ICU mortality between groups, yet the risk ratio for hospital mortality was lower among those randomized to the restrictive threshold [21]. While these differences in mortality outcomes may be due to unmeasured confounding in our observational data, our present findings still do not indicate an increased risk of harm for transfused patients with a lower pre-transfusion hemoglobin value (i.e., below $70 \mathrm{~g} / \mathrm{L}$ ).

\section{Study limitations}

There are limitations to the present study worth noting. While we were able to capitalize on population-based administrative and clinical data sources, we may have excluded possible confounders and/or introduced other sources of bias due to the retrospective observational design of the study. Moreover, we did not have adequate recording in the data of the exact reason for a given transfusion across all ICUs. Therefore, patients may have been misclassified and actually had hemorrhage or ischemia. While our conservative inclusion criteria were applied in attempt to mitigate such misclassification, supplementing secondary data sources with medical record audits may additionally aid in overcoming misclassification.

Given the de-identified nature of the data, we were unable to examine the association of factors such as hospital type (i.e., teaching hospital, community hospital) and level of physician experience in our logistic regression analyses. We were also unable to identify the consequences directly associated with a potentially inappropriate transfusion (i.e., transfusion-related complications) due to the retrospective design of our study. Lastly, the present analysis focused on RBC transfusion events in medical-surgical ICUs in one Canadian province; the generalizability of our findings to other Canadian and/or international critical care contexts is unclear. Future studies designed with more detailed prospective data collection and with inter-provincial or international cohort comparisons could, therefore, expand understanding in these areas.

\section{Conclusions}

The present study examined the utilization and costs of $\mathrm{RBC}$ transfusion practices within nine medical-surgical ICUs and identified that more than half are still provided above guideline-recommended pre-transfusion hemoglobin thresholds. There is still a large opportunity for improvement in RBC transfusion practices from a patient safety, quality, and financial perspective. Future work to fully characterize the rationale for transfusion decisions as well as understand the factors that underlie the behavior, whether at the environmental or individual physician level, may aid in developing targeted interventions to eliminate overuse $[29,30]$. Importantly, the lessons learned from the present study may also help to inform larger-scale blood management programs beyond critical care [38]. With increasing pressures faced by healthcare systems globally to improve quality of care in light of scarce resources, such efforts to address medical overuse are of increasing necessity.

\section{Additional files}

Additional file 1: Operational definitions for exclusion criteria. (DOCX $31 \mathrm{~kb}$ ) 
Additional file 2: Characteristics of ICU patients associated with included RBC transfusions, stratified by pre-transfusion hemoglobin values. (DOCX $93 \mathrm{~kb}$ )

Additional file 3: Association between study month and percentage of RBC transfusions with a hemoglobin value of $70 \mathrm{~g} / \mathrm{L}$ or more. (DOCX $22 \mathrm{~kb}$ )

\section{Abbreviations}

APACHE: Acute Physiology and Chronic Health Evaluation; CAD: Canadian dollars; Cl: Confidence interval; $\mathrm{ClHI}$ : Canadian Institute for Health Information; DAD: Discharge Abstract Database; ICU: Intensive care unit; IQR: Interquartile range; LOS: Length of stay; OR: Odds ratio; RBC: Red blood cell; SD: Standard deviation; SOFA: Sequential Organ Failure Assessment

\section{Acknowledgements}

Not applicable.

\section{Funding}

LJJS is supported by an Alberta Innovates-Health Solutions (AIHS) Graduate Studentship Award (Record Number: 201500076). The funding body had no role in the design of the study and collection, analysis, and interpretation of data and in writing the manuscript. There are no other financial disclosures.

\section{Availability of data and materials}

The datasets generated and/or analysed during the current study are not publicly available due data privacy restrictions, but aggregate summaries may be available from the corresponding author on reasonable request.

\section{Authors' contributions}

LJJS, TWN, HTS, DAZ, and FMC contributed the design of the study, interpretation of the data, review of the manuscript, and approval of the manuscript. LJJS and FMC contributed the management of data and preparation of the manuscript. LJJS contributed the analysis of data. All authors read and approved the final manuscript.

\section{Ethics approval and consent to participate}

Research ethics approval was obtained from the Conjoint Health Research Ethics Board (CHREB) of the University of Calgary (Ethics ID: REB15-2001). Consent of participants was not required due to the de-identified nature of the data and the retrospective study design.

\section{Consent for publication}

Not applicable.

\section{Competing interests}

The authors declare that they have no competing interests.

\section{Publisher's Note}

Springer Nature remains neutral with regard to jurisdictional claims in published maps and institutional affiliations.

\section{Author details}

${ }^{1}$ Department of Community Health Sciences, Cumming School of Medicine, University of Calgary, 3D18, Teaching Research and Wellness Building, 3280 Hospital Drive NW, Calgary, Alberta T2N 4N1, Canada. ${ }^{2} \mathrm{O}$ 'Brien Institute for Public Health, University of Calgary, 3280 Hospital Drive NW, Calgary, Alberta T2N 4N1, Canada. ${ }^{3}$ Department of Critical Care Medicine, Cumming School of Medicine, University of Calgary, Foothills Medical Centre, 140329 Street NW, Calgary, Alberta T2N 2T9, Canada. ${ }^{4}$ Department of Critical Care Medicine, Alberta Health Services and Faculty of Medicine and Dentistry, University of Alberta, Room 2-124 Clinical Sciences Building, 8440 - 112 Street, Edmonton, Alberta T6G 2B7, Canada.
Received: 7 January 2019 Accepted: 22 March 2019

Published online: 04 April 2019

\section{References}

1. Chassin MR, Galvin RW. The urgent need to improve health care quality. Institute of Medicine National Roundtable on Health Care Quality. JAMA 1998:280(11):1000-5.

2. Brownlee S, Chalkidou K, Doust J, Elshaug AG, Glasziou P, Heath I, et al. Evidence for overuse of medical services around the world. Lancet. 2017; 390(10090):156-68.

3. Saini V, Garcia-Armesto S, Klemperer D, Paris V, Elshaug AG, Brownlee S, et al. Drivers of poor medical care. Lancet. 2017;390(10090):178-90.

4. Elshaug AG, Rosenthal MB, Lavis JN, Brownlee S, Schmidt H, Nagpal S, et al. Levers for addressing medical underuse and overuse: achieving high-value health care. Lancet. 2017;390(10090):191-202.

5. MacLeod S, Musich S, Hawkins K, Schwebke K. Highlighting a common quality of care delivery problem: overuse of low-value healthcare services. J Healthc Qual. 2017:40:201-8.

6. The Joint Commission and the American Medical Association-Convened Physician Consortium for Performance Improvement ${ }^{\circledast}$. Proceedings from the National Summit on Overuse 2012. Available from: https://www. jointcommission.org/overuse summit/. Accessed 5 Oct 2018.

7. Napolitano LM, Kurek S, Luchette FA, Anderson GL, Bard MR, Bromberg W et al. Clinical practice guideline: red blood cell transfusion in adult trauma and critical care. J Trauma. 2009;67(6):1439-42.

8. Klein HG, Spahn DR, Carson JL. Red blood cell transfusion in clinical practice. Lancet. 2007;370(9585):415-26.

9. Vincent JL, Baron J-F, Reinhart K, Gattinoni L, Thijs L, Webb A, et al. Anemia and blood transfusion in critically ill patients. JAMA. 2002;288(12):1499-507.

10. Corwin HL, Krantz SB. Anemia of the critically ill:"Acute" anemia of chronic disease. Crit Care Med. 2000;28(8):3098-9.

11. Corwin HL, Parsonnet KC, Gettinger A. RBC transfusion in the ICU: is there a reason? Chest. 1995;108(3):767-71.

12. Delaney M, Wendel S, Bercovitz RS, Cid J, Cohn C, Dunbar NM, et al. Transfusion reactions: prevention, diagnosis, and treatment. Lancet. 2016; 388(10061):2825-36

13. Toy $P$, Gajic O, Bacchetti $P$, Looney MR, Gropper MA, Hubmayr R, et al. Transfusion-related acute lung injury: incidence and risk factors. Blood. 2012 119(7):1757-67.

14. Shander A, Hofmann A, Ozawa S, Theusinger OM, Gombotz H, Spahn DR. Activity-based costs of blood transfusions in surgical patients at four hospitals. Transfusion. 2010;50(4):753-65.

15. Carson JL, Guyatt G, Heddle NM, Grossman BJ, Cohn CS, Fung MK, et al. Clinical practice guidelines from the AABB: red blood cell transfusion thresholds and storage. JAMA. 2016;316(19):2025-35.

16. Hebert PC, Wells G, Blajchman MA, Marshall J, Martin C, Pagliarello G, et al. A multicenter, randomized, controlled clinical trial of transfusion requirements in critical care. Transfusion Requirements in Critical Care Investigators, Canadian Critical Care Trials Group. N Engl J Med 1999;340(6): 409-417.

17. Lacroix J, Hebert PC, Hutchison JS, Hume HA, Tucci M, Ducruet T, et al. Transfusion strategies for patients in pediatric intensive care units. N Engl J Med. 2007;356(16):1609-19.

18. Hebert PC, Wells G, Marshall J, Martin C, Tweeddale M, Pagliarello G, et al. Transfusion requirements in critical care: a pilot study. JAMA. 1995;273(18): 1439-44.

19. Walsh TS, Boyd JA, Watson D, Hope D, Lewis S, Krishan A, et al. Restrictive versus liberal transfusion strategies for older mechanically ventilated critically ill patients: a randomized pilot trial. Crit Care Med. 2013;41(10): 2354-63.

20. Holst LB, Haase N, Wetterslev J, Wernerman J, Guttormsen AB, Karlsson S, et al. Lower versus higher hemoglobin threshold for transfusion in septic shock. N Engl J Med. 2014;371(15):1381-91.

21. Carson JL, Stanworth SJ, Roubinian N, Fergusson DA, Triulzi D, Doree C, et al. Transfusion thresholds and other strategies for guiding allogeneic red blood cell transfusion. Cochrane Database Syst Rev. 2016;10:Cd002042.

22. Bagshaw SM, Wang X, Zygun DA, Zuege D, Dodek P, Garland A, et al. Association between strained capacity and mortality among patients admitted to intensive care: a path-analysis modeling strategy. J Crit Care. 2018:43:81-7. 
23. eCritical Alberta. cited 2017 December 8. Available from: ref: http://www. albertahealthservices.ca/assets/about/scn/ahs-scn-sb-cc-ecritical.pdf. Accessed 8 Dec 2017.

24. Canadian Institute for Health Information. Discharge Abstract Database Metadata 2017. Available from: https://www.cihi.ca/en/discharge-abstractdatabase-metadata. Accessed 8 Dec 2017.

25. Lagerquist O, Poseluzny D, Werstiuk G, Slomp J, Maier M, Nahirniak S, et al. The cost of transfusing a unit of red blood cells: a costing model for Canadian hospital use. ISBT Science Series. 2017;12:375-80.

26. Elzik ME, Dirschl DR, Dahners LE. Correlation of transfusion volume to change in hematocrit. Am J Hematol. 2006:81(2):145-6.

27. Choosing Wisely. The Choosing Wisely Lists: choosing wisely, an initiative of the American Board of Internal Medicine 2017 2016. Available from: http:// www.choosingwisely.org/clinician-lists/. Accessed 5 Oct 2018.

28. Carson JL, Grossman BJ, Kleinman S, Tinmouth AT, Marques MB, Fung MK, et al. Red blood cell transfusion: a clinical practice guideline from the AABB. Ann Intern Med. 2012;157(1):49-58.

29. Francis JJ, Stockton C, Eccles MP, Johnston M, Cuthbertson BH, Grimshaw $\mathrm{JM}$, et al. Evidence-based selection of theories for designing behaviour change interventions: using methods based on theoretical construct domains to understand clinicians' blood transfusion behaviour. Br J Health Psychol. 2009;14(Pt 4:625-46.

30. Islam R, Tinmouth AT, Francis JJ, Brehaut JC, Born J, Stockton C, et al. A cross-country comparison of intensive care physicians' beliefs about their transfusion behaviour: a qualitative study using the theoretical domains framework. Implement Sci. 2012;7(1):93.

31. Al-Faris L, Al-Fares AR, Abdul Malek K, Omran A, Al-Humood S. Blood transfusion practice in critically ill patients: a single institutional experience Med Princ Pract. 2012;21(6):560-5.

32. Netzer G, Liu X, Harris AD, Edelman BB, Hess JR, Shanholtz C, et al. Transfusion practice in the intensive care unit: a 10-year analysis. Transfusion. 2010;50(10):2125-34.

33. Surial B, Burkhart A, Terliesner N, Morgenthaler M, Bächli E. Adherence to transfusion guidelines: are we prepared for the Smarter Medicine or Choosing Wisely initiative. Swiss Med Wkly. 2015;145:w14084.

34. Anahita Sadeghi M, Safieh Belali M, Ali Ali Asgari M, Zahra Morovat M, Reza Malekzadeh M. Inappropriate packed RBC transfusion in a tertiary care center. Arch Iran Med. 2017;20(2):83

35. Chohan SS, McArdle F, McClelland DB, Mackenzie SJ, Walsh TS. Red cell transfusion practice following the transfusion requirements in critical care (TRICC) study: prospective observational cohort study in a large UK intensive care unit. Vox Sang. 2003;84(3):211-8.

36. Jairath $\mathrm{V}$. Acute upper gastrointestinal bleeding-time for some new triggers? Transfus Med. 2013;23(3):139-41.

37. Rossaint R, Bouillon B, Cerny V, Coats TJ, Duranteau J, Fernández-Mondéjar E, et al. The STOP the bleeding campaign. Crit Care. 2013;17(2):136.

38. Sadana D, Pratzer A, Scher U, Saag HS, Adler N, Volpicelli FM, et al. Promoting high-value practice by reducing unnecessary transfusions with a patient blood management program. JAMA Intern Med. 2017;178:116-22.

Ready to submit your research? Choose BMC and benefit from:

- fast, convenient online submission

- thorough peer review by experienced researchers in your field

- rapid publication on acceptance

- support for research data, including large and complex data types

- gold Open Access which fosters wider collaboration and increased citations

- maximum visibility for your research: over $100 \mathrm{M}$ website views per year

At BMC, research is always in progress.

Learn more biomedcentral.com/submissions 